\title{
Intralingual Route of Administration
}

National Cancer Institute

\section{Source}

National Cancer Institute. Intralingual Route of Administration. NCI Thesaurus. Code C79138.

Administration of a drug into the tongue. 